\title{
Sympathovagal Imbalance, Cardiometabolic Risks and Hypertension Status are Linked to Depression in Women Having Risk Factors for Pregnancy-induced Hypertension
}

\author{
Gopal Krushna Pall ${ }^{1, *}$, Syed Habeebullah ${ }^{2}$, Manivannan Subhaa ${ }^{1}$, Pravati Pal'
}

\section{Gopal Krushna Pal ${ }^{1, *}$, Syed Habeebullah", Manivannan Subha ${ }^{1}$, Pravati Pal ${ }^{1}$}

\section{'Department of Physiology, Obstetrics and Gynecology, Jawaharlal Institute of Medical Education and Research (JIPMER), Puducherry, INDIA. ${ }^{2}$ Department of Biochemistry, Pondicherry Institute of Medical Sciences, Puducherry, INDIA. \\ *Correspondence \\ Dr. Gopal Krushna Pal}

Senior Professor, Department of Physiology, JIPMER, Pondicherry-605 006, INDIA.

Phone: +91-9344291160

Email: drgkpa|@gmail.com

\section{History}

- Submission Date: 24-04-2021;

- Review completed: 05-05-2021;

- Accepted Date: 20-05-2021.

DOI : 10.5530/ijcep.2021.8.2.15

Article Available online

http://www.ijcep.org

\section{Copyright}

(C) 2021 Phcog.Net. This is an openaccess article distributed under the terms of the Creative Commons Attribution 4.0 International license.

\begin{abstract}
Background and Aim: Pregnancy is a physiological state in which there are cardiovascular, autonomic, hemodynamic and psychological changes. Increase in incidence of stress and depression in antenatal period has been reported. Autonomic changes in pregnancy-induced hypertension $(\mathrm{PIH})$ and its dysfunction in depression are well documented. However, there is no report of contribution of sympathovagal imbalance (SVI) and cardiometabolic alterations to stress and depression in PIH. Methods: In this case-control study, we assessed and analyzed cardiovascular autonomic functions including heart rate variability (HRV) and cardiometabolic risks (CMR) between pregnant women having risks of $\mathrm{PIH}(n=62)$ and normal healthy pregnant women $(n=68)$. The perceived stress scale (PSS-10) and Quality of Life (QoL) were used to evaluate depressive symptoms and perceived stress. The HRV and CMR parameters were correlated with PSS. Multiple regression analysis was performed individually to study their association with PSS. Logistic regression was done to determine the prediction of hypertension/prehypertension status by PSS. Results: There was increase in heart rate and blood pressure, decreased HRV and increased markers of insulin resistance, atherogenic lipid profile, markers of inflammation, oxidative stress and vascular endothelial dysfunction in PIH risk subjects compared to control subjects. Parameters of SVI and decreased cardiovagal modulation and CMR were significantly correlated and associated with PSS. PSS had independent prediction of prehypertension/hypertension status in the study group. Conclusion: Findings of the present study indicate that there is considerable SVI and CMR in PIH. It appears that depression is the major cause of SVI and decreased cardiovagal modulation in $\mathrm{PIH}$, and retrograde inflammation and vascular endothelial dysfunction could be the potential mechanisms of depression mediated SVI in PIH.

Key words: Pregnancy-induced hypertension, Sympathovagal imbalance, Cardiovagal inhibition, Depression, Perceives stress scale, Cardiometabolic risks.
\end{abstract}

\section{INTRODUCTION}

Pregnancy is associated with multiple physiological and behavioral changes that predispose pregnant women to many health conditions detrimental to maternal and child well-being. ${ }^{[1]}$ Diagnostic and statistical manual of mental disorders 5 (DSM 5) recognise peripartum depression as a major depressive episode (MDD) occurring during or after pregnancy. ${ }^{[2]}$ Antenatal depression in coastal South has been reported to be $16.3 \%,{ }^{[3]}$ and similar results were obtained by Rahman A et al., who found prevalence of perinatal mental disorders to be $15.6 \%$ in low and middle income countries in a meta-analysis study. ${ }^{[4]}$ As demonstrated in various studies, perinatal depression is associated with poor maternal and foetal outcomes. ${ }^{[3,5]}$ In these studies, Perceived Stress Scale (PSS), ${ }^{[6]}$ was used for assessing stress of pregnant women. ${ }^{[3-5]}$ Recently we have reported association of sympathovagal imbalance (SVI), decreased baroreflex sensitivity (BRS) and

Cite this article: Pal GK, Habeebullah S, Subha M, Pal P. Sympathovagal Imbalance, Cardiometabolic Risks and Hypertension Status are Linked to Depression in Women Having Risk Factors for Pregnancy-induced Hypertension. Int J Clin Exp Physiol. 2021;8(2):59-64. 
association between depression and hypertension is an important factor that should be evaluated early and treated effectively during pregnancy. Reports indicate that psychological factors such as depression and/ or depressive symptoms associated with gestational hypertension have increased greatly in recent years. ${ }^{[13,14]}$ However, till date mechanisms that aggravate depression in PIH and the factors that precipitate depressive symptoms in pregnancy have not been systematically elucidated.

We have reported sympathovagal imbalance (SVI), decreased baroreflex sensitivity (BRS) and increased cardiovascular (CV) risks in pregnancyinduced hypertension (PIH). ${ }^{[15-18]}$ Autonomic imbalance has been reported to be associated with depression. ${ }^{[19,20]}$ However, till date the link of PSS to sympathovagal imbalance in pregnancy and PIH has not been assessed. Therefore, this study was conducted to evaluate if there any association between depression and hypertensive disorders status, and if SVI contributes to depression in PIH.

\section{MATERIALS AND METHODS}

The present case-control study was conducted in the Department of Physiology, Jawaharlal Institute of Postgraduate Medical Education and Research (JIPMER), Pondicherry, India. After obtaining approval of the project plan from research and ethics committees of JIPMER, 140 subjects (68 in control group, 72 in study group) were recruited from the Outpatient Department (OPD) of the Obstetrics and Gynecology department of JIPMER during the period of January, 2010 to December, 2012. Written informed consent was obtained from all the participants prior to initiation of the study.

\section{Inclusion and Exclusion Criteria}

Subjects of study group included pregnant women who had risk factors for PIH. The subjects of control group included normal pregnant women without having risk factors for PIH. Inclusion criteria of risk factors for PIH were kept same as reported earlier, ${ }^{[15]}$ such as family history of preeclampsia, preeclampsia in previous pregnancy, extremes of reproductive age, body mass index $(\mathrm{BMI})>35$, diastolic blood pressure (DBP) $>80 \mathrm{~mm} \mathrm{Hg}$ at the first visit, first pregnancy, multiple pregnancy, underlying medical conditions (diabetes mellitus, renal disease preexisting hypertension) etc. Pregnant women having any other medical illness or receiving medications for other problems were excluded from the study.

\section{Patient Recruitment and Baseline Measurements}

The subjects attending obstetrics OPD for their regular check-ups in the third trimester of gestation were recruited for the study. They were reported to polygraph laboratory of physiology department for recording of various parameters at 36 to 38 weeks of pregnancy, about two hours after a light breakfast devoid of coffee or tea. Height and weight were measured to calculate body mass index (BMI). Blood pressure (BP) was recorded using the automatic non-invasive BP monitor, Omron, HEM 7203 model (Omron Healthcare Co., Kyoto, Japan). Heart rate, systolic $\mathrm{BP}$ and diastolic BP were noted from the display screen of BP monitor, and mean arterial pressure (MAP) was calculated. Rate pressure product $(\mathrm{RPP})$ was calculated using the formula, $\mathrm{RPP}=$ systolic pressure $\times$ heart rate $\times 10^{-2}{ }^{[21]}$

\section{Estimation of Biochemical Parameters}

Five $\mathrm{ml}$ of venous blood was collected from all the subjects of both the groups in all the three trimesters for estimation of fasting blood glucose (FBG), serum insulin, lipid profile (TC: Total serum cholesterol; TG: Triglyceride; LDL: Low-density lipoprotein; VLDL: Very low-density lipoprotein), malonaldehyde(MDA), by using biochemistry autoanalyzer. HOMA-IR and atherogenic index (AI) were calculated. Inflammatory markers such as high-sensitive C-reactive protein (hsCRP) (Calbiotech, USA), tumour necrosis factor $\alpha$ (TNF- $\alpha$ ), interleukin-6 (IL-6) (Diaclone, France), were measured using ELISA kit according to manufacturer instructions. Nitric oxide derivatives (nitrate and nitrite) and endothelin 1 (ET-1) were estimated using chemical method (Elabscience, USA).

\section{HRV Recording}

Following $10 \mathrm{~min}$ of supine rest in polygraph laboratory (room temperature maintained at $25^{\circ} \mathrm{C}$ ), basal heart rate (BHR) and blood pressures (diastolic and systolic) were recorded. For recording of shortterm HRV, recommendation of the Task Force on HRV and our previous methodology of HRV recording were followed. ${ }^{[15,22]}$ For the purpose, ECG electrodes were connected and Lead II ECG was acquired at a rate of 1000 samples/second during supine rest using BIOPAC MP 100 data acquisition system (BIOPAC Inc., USA). The data was transferred from BIOPAC to a windows-based PC with Acqkowledge software version 3.8.2. Ectopics and artifacts were removed from the recorded ECG. RR tachogram was extracted from the edited $256 \mathrm{sec}$ ECG using the R wave detector in the Acqkowledge software and saved in ASC-II format which was later used offline for short term HRV analysis. HRV analysis was done using the HRV analysis software version 1.1 (Bio-signal Analysis group, Finland). Variance, defined as power in a portion of the total spectrum of frequencies was measured in milliseconds squared $\left(\mathrm{ms}^{2}\right)$. Frequency-domain indices of HRV such as total power (TP), normalized low-frequency power (LFnu), normalized high-frequency power (HFnu), ratio of low-frequency to high-frequency power (LF-HF ratio), and time-domain indices such as square root of the mean of the sum of the squares of the differences between adjacent NN intervals (RMSSD), standard deviation of normal to normal interval (SDNN), number of interval differences of successive NN intervals greater than $50 \mathrm{~ms}$ (NN50) and the proportion derived by dividing NN50 by the total number of NN intervals (pNN50) were recorded.

\section{Assessment of Depression by PSS-10 and Quality of Life Scale}

The level of depression was assessed using Perceived Stress Scale (PSS$10),{ }^{[23]}$ and Quality of Life scale (QoL). ${ }^{[24]}$ The PSS-10 is a 10 items selfreporting questionnaire with each response scored from 0 to 4 points and total scores ranged from 0 to 40 points. PSS-10 scores are classified from 0 to 13 (low), 14-26 (moderate), and 27-40 (severe perceived stress). For QoL scale, subjects are asked to indicate on a 4-point scale how often in the past week they have felt in accordance with 11 different statements. Responses are summed for a total score, higher scores indicating more depressive symptomology. In the present study, Flanagan Quality of Life (QoL) scale was used to assess the quality of life of the participants. It is composed of 16 items which covers 5 domains. The domains include physical and material well-being; relations with other people; social, community and civic activities; personal development and fulfilment; and recreation. This questionnaire is a 7 -point scale ranging from delighted to terrible. The total score ranges from 16-112. The average total score for healthy population is about 90 .

\section{Statistical Analysis of Data}

SPSS version 13 (SPSS Software Inc., Chicago, IL, USA) was used for statistical analysis. All the data were expressed as mean \pm SD. Normality of data was tested by Kolmogorov Smirnov test. For parametric data, the level of significance between the groups was tested by Student's unpaired $t$ test and for nonparametric data Welch's corrected $t$ test was used. The independent contribution of various parameters of cardiometabolic risks to PSS-10 was assessed by multiple regression analysis. Independent prediction of PSS-10 to hypertension status in third trimester was 
assessed by multivariate logistic regression. The $\mathrm{p}$ value less than 0.05 was considered statistically significant.

\section{RESULTS}

There was no significant difference in age of subjects of both the groups. $\mathrm{BMI}, \mathrm{BHR}, \mathrm{BP}$ and RPP in the study group were significantly more $(\mathrm{P}<0.0001)$ at $36^{\text {th }}$ week compared to the control group (Table 1$)$. Among the HRV indices, the TP, HFnu and time-domain indices (RMSSD, SDNN, NN50, pNN50) were significantly reduced $(\mathrm{P}<0.0001)$ and LFnu and LF-HF ratio were significantly increased $(\mathrm{P}<0.0001)$ in study group compared to control group (Table 1). All blood glucose-related parameters including HOMA-IR, lipid profile (except HDL) and lipid risk factors, inflammatory and oxidative stress markers were significantly high in study group compared to control group (Table 2). Endothelin-1 was significantly increased and NO was significantly decreased in study group compared to control group (Table 2). The PSS score significantly increased and QOL was significantly decreased in study group compared to control group (Table 2).

There was no significant correlation of any of the parameter with PSS in control group (Table 3). In study group, except BMI, hsCRP and

Table 1: Age, BMI and cardiovascular parameters including HRV in control group (normal pregnant women without having risk factors of pregnancy-induced hypertension) and study group (pregnant women having risk factors for pregnancy-induced hypertension), at $36^{\text {th }}$ week of pregnancy.

$\begin{array}{cccc} & \begin{array}{c}\text { Control group } \\ (\mathbf{n}=68)\end{array} & \begin{array}{c}\text { Study group } \\ (\mathbf{n}=72)\end{array} & \text { P value } \\ \text { Age (Yrs) } & 27.58 \pm 3.52 & 26.85 \pm 4.10 & 3.5680 \\ \text { Weight (Kg) } & 65.50 \pm 5.24 & 71.86 \pm 5.74 & 0.0002 \\ \left.\text { BMI (Kg/m })^{2}\right) & 25.72 \pm 3.10 & 28.92 \pm 4.75 & <0.0001 \\ \text { BHR (per min) } & 82.86 \pm 8.50 & 95.25 \pm 9.50 & <0.0001 \\ \text { SBP (mmHg) } & 110.56 \pm 10.42 & 131.98 \pm 12.36 & <0.0001 \\ \text { DBP (mmHg) } & 71.08 \pm 6.25 & 86.42 \pm 8.70 & <0.0001 \\ \text { RPP (mmHg/min) } & 91.60 \pm 9.40 & 125.70 \pm 13.15 & <0.0001 \\ \text { HRV Parameters } & & & \\ \left.\text { TP (ms }{ }^{2}\right) & 772.20 \pm 267.45 & 438.25 \pm 120.20 & <0.0001 \\ \text { LFnu } & 45.80 \pm 17.22 & 62.25 \pm 20.32 & <0.0001 \\ & & & \\ \text { HFnu } & 54.20 \pm 18.24 & 37.75 \pm 12.50 & <0.0001 \\ \text { LF-HF ratio } & 0.84 \pm 0.28 & 1.64 \pm 0.49 & <0.0001 \\ \text { RMSSD } & 44.53 \pm 18.70 & 25.37 \pm 7.42 & <0.0001 \\ \text { SDNN } & 40.40 \pm 15.45 & 20.22 \pm 6.86 & <0.0001 \\ \text { NN50 } & 44.40 \pm 17.35 & 21.50 \pm 7.68 & <0.0001 \\ \text { pNN50 } & 22.13 \pm 9.40 & 10.21 \pm 3.53 & <0.0001\end{array}$

The data presented are mean \pm SD. Comparison was done using Student's unpaired $t$ test. $P$ value $<0.05$ was considered statistically significant. BMI: Body mass index; BHR: Basal heart rate; SBP: Systolic blood pressure; DBP: Diastolic blood pressure; RPP: Rate-pressure product; TP: Total power of HRV; LFnu: Normalized low-frequency (LF) power; HFnu: Normalized high-frequency (HF) power; RMSSD: The square root of the mean of the sum of the squares of the differences between adjacent NN intervals; SDNN: Standard deviation of normal to normal interval; NN50: The number of interval differences of successive NN intervals greater than 50; pNN50: The proportion derived by dividing $\mathrm{NN} 50$ by the total number of $\mathrm{NN}$ intervals.
MDA, all parameters were significantly correlated with PSS. On multiple regression analysis demonstrated independent contribution of RPP, TP, LF-HR ratio, IL-6, TNF- $\boldsymbol{\alpha}$, endothelin-1, and NO to PSS (Table 4). However, there was no significant contribution of HOMA-IR, AI and MDA to PSS.

On multivariate logistic regression analysis to determine the predictive power of PSS in the development of hypertension or prehypertension status, it was found the significance of prediction was more in control group $(\mathrm{P}=0.003)$ compared to study group $(\mathrm{P}=0.006)$ (Table 5$)$.

\section{DICUSSION}

In the present study, PSS significantly predicted the prehypertension and hypertension status in study group subjects (Table 5), which indicates that the level of depression is directly linked to the rise in BP in pregnant

Table 2: Biochemical parameters, PSS and QOL scores in control and study groups in third trimester of gestation.

\begin{tabular}{lcll} 
& \multicolumn{1}{c}{$\begin{array}{c}\text { Control group } \\
(\mathbf{n}=68)\end{array}$} & \multicolumn{1}{c}{$\begin{array}{c}\text { Study group } \\
(\mathbf{n}=72)\end{array}$} & P value \\
Glucose related parameters & & \\
FBG $(\mathrm{mg} / \mathrm{dL})$ & $81.20 \pm 10.56$ & $110.70 \pm 10.30$ & $<0.0001$ \\
Insulin $(\mu \mathrm{IU} / \mathrm{mL})$ & $5.30 \pm 1.68$ & $19.30 \pm 3.85$ & $<0.0001$ \\
HOMA-IR & $1.25 \pm 0.31$ & $5.30 \pm 1.12$ & $<0.0001$
\end{tabular}

Lipid related parameters

$\begin{array}{llll}\text { TC }(\mathrm{mg} / \mathrm{dL}) & 148.80 \pm 25.20 & 170.80 \pm 27.20 & <0.0001 \\ \text { TG }(\mathrm{mg} / \mathrm{dL}) & 81.70 \pm 17.40 & 120.76 \pm 22.30 & <0.0001 \\ \text { LDL }(\mathrm{mg} / \mathrm{dL}) & 87.50 \pm 19.10 & 125.30 \pm 24.50 & <0.0001 \\ \text { VLDL }(\mathrm{mg} / \mathrm{dL}) & 16.21 \pm 3.45 & 25.08 \pm 5.06 & <0.0001 \\ \text { HDL }(\mathrm{mg} / \mathrm{dL}) & 48.17 \pm 5.35 & 34.42 \pm 4.58 & <0.0001 \\ \text { TC/HDL } & 3.07 \pm 0.42 & 4.97 \pm 0.68 & <0.0001 \\ \text { TG/HDL } & 1.70 \pm 0.25 & 3.50 \pm 0.52 & <0.0001 \\ \text { Atherogenic index } & 0.23 \pm 0.08 & 0.57 \pm 0.11 & <0.0001\end{array}$

Inflammatory and OS parameters

$\begin{array}{llll}\text { hsCRP }(\mathrm{ng} / \mathrm{dL}) & 396.40 \pm 65.20 & 948.30 \pm 178.20 & <0.0001 \\ \mathrm{IL}-6(\mathrm{pg} / \mathrm{ml}) & 72.25 \pm 8.68 & 135.60 \pm 12.30 & <0.0001 \\ \mathrm{TNF}-\alpha(\mathrm{pg} / \mathrm{ml}) & 152.80 \pm 13.32 & 284.55 \pm 18.35 & <0.0001 \\ \mathrm{MDA}(\mu \mathrm{M} / \mathrm{L}) & 1.86 \pm 0.45 & 5.47 \pm 0.98 & <0.0001\end{array}$

Endothelial dysfunction parameters

Endothelin-1 ( $\mu \mathrm{g} / \mathrm{L}) \quad 6.86 \pm 0.85 \quad 10.22 \pm 0.1 .07 \quad<0.0001$

$\mathrm{NO}(\mu \mathrm{mol} / \mathrm{L}) \quad 32.15 \pm 3.46 \quad 21.05 \pm 2.85 \quad<0.0001$

Depression parameters

$\begin{array}{llll}\text { PSS } & 15.10 \pm 3.60 & 21.83 \pm 5.52 & 0.0001 \\ \text { QoL } & 102.56 \pm 9.20 & 86.21 \pm 7.90 & 0.0001\end{array}$

The data presented are mean \pm SD. Comparison was done using Student's unpaired $t$ test. $P$ value $<0.05$ was considered statistically significant. FBG: Fasting blood glucose; HOMA-IR: homeostatic model assessment of insulin resistance; TC: Total serum cholesterol; TG: Triglyceride; LDL: Low-density lipoprotein; VLDL: Very low-density lipoprotein; OS: Oxidative stress; hsCRP: high-sensitive $C$ reactive protein; IL-6: Interleukin 6; TNF- $\alpha$ : Tumour necrosis factor $\alpha$; MDA: Malondialdehyde; NO: Nitric oxide; PSS: Perceived stress scale; QoL: Quality of life. 
Table 3: Correlation of PSS with various cardiometabolic parameters in both control and study group in $3^{\text {rd }}$ trimester of pregnancy.

\begin{tabular}{ccccc} 
& $\begin{array}{c}\text { Control } \\
\text { group }\end{array}$ & $\begin{array}{c}\text { Study } \\
\text { group }\end{array}$ & & \\
BMI & $\boldsymbol{r}$ & $\mathbf{P}$ & $\boldsymbol{r}$ & $\mathbf{P}$ \\
BHR & -0.082 & 0.391 & 0.105 & 0.341 \\
SBP & -0.180 & 0.091 & 0.268 & 0.040 \\
RPP & -0.179 & 0.092 & 0.305 & 0.012 \\
TP & -0.195 & 0.072 & 0.327 & 0.009 \\
LH-HF ratio & 0.210 & 0.077 & -0.386 & 0.005 \\
HOMA-IR & -0.205 & 0.080 & 0.260 & 0.043 \\
Atherogenic index & -0.236 & 0.058 & 0.437 & 0.001 \\
hs-CRP & -0.240 & 0.057 & 0.430 & 0.001 \\
IL-6 & -0.182 & 0.091 & 0.240 & 0.056 \\
TNF- $\boldsymbol{\alpha}$ & -0.180 & 0.092 & 0.305 & 0.012 \\
MDA & -0.196 & 0.072 & 0.327 & 0.009 \\
Endothelin-1 & -0.095 & 0.294 & 0.196 & 0.091 \\
NO & -0.203 & 0.081 & 0.350 & 0.007 \\
\hline
\end{tabular}

The $\mathrm{p}$ values less than 0.05 was considered significant. PSS: Perceived stress scale; BMI: Body mass index; WHR: Waist-hip ratio; BHR: Basal heart rate; SBP: Systolic blood pressure; RPP: Rate-pressure product; TP: Total power of HRV; LF-HF ratio: Ratio of normalized low-frequency (LF) power normalized high-frequency (HF) power; HOMA-IR: homeostatic model assessment of insulin resistance; hsCRP: high-sensitive C reactive protein; IL-6: Interleukin 6 ; TNF- $\alpha$ : Tumour necrosis factor $\alpha$; MDA: Malondialdehyde; NO: nitric oxide.

Table 4: Multiple regression analysis to assess independent contribution of various important cardiometabolic parameters to PSS (as dependent variable) in third trimester in the study group.

\begin{tabular}{ccccc} 
Independent & $\begin{array}{c}\text { Standardized } \\
\text { variables }\end{array}$ & $\begin{array}{c}\text { Confidence interval } \\
\text { regression } \\
\text { coefficient } \\
\text { beta }\end{array}$ & $\begin{array}{c}\text { Lower } \\
\text { limit }\end{array}$ & $\begin{array}{c}\text { Upper } \\
\text { limit }\end{array}$ \\
\hline RPP & 0.327 & 0.021 & 0.108 & 0.011 \\
TP & -0.416 & 0.002 & 0.185 & 0.007 \\
LF-HF ratio & 0.308 & -0.032 & 0.156 & 0.025 \\
HOMA-IR & 0.122 & 0.015 & 0.005 & 0.104 \\
AI & 0.157 & 0.005 & 0.088 & 0.092 \\
IL-6 & 0.292 & -0.003 & 0.145 & 0.031 \\
TNF- $\alpha$ & 0.308 & 0.032 & 0.206 & 0.025 \\
MDA & 0.244 & 0.001 & 0.072 & 0.062 \\
Endothelin- 1 & 0.315 & 0.033 & 0.134 & 0.018 \\
NO & -0.300 & -0.002 & 0.135 & 0.027
\end{tabular}

$\mathrm{P}$ values $<0.05$ were considered significant. RPP: Rate-pressure product; TP: Total power of HRV; LF-HF ratio: Ratio of normalized low-frequency (LF) power normalized high-frequency (HF) power; HOMA-IR: homeostatic model assessment of insulin resistance; AI: Atherogenic index; IL-6: Interleukin 6; TNF- $\alpha$ : Tumour necrosis factor $\alpha$; MDA: Malondialdehyde; NO: nitric oxide.
Table 5: Univariate logistic regression analysis of PSS (as dependent variable) with prehypertension / hypertension status (as independent variables) in study group population at $36^{\text {th }}$ week of gestation, adjusted for age, gender and BMI.

\begin{tabular}{lcc} 
& OR (95\% C.I.) & P value \\
\hline Study Group & $3.86(1.45$ to 10.582$)$ & 0.004
\end{tabular}

$\mathrm{P}<0.05$ considered significant; PSS: Perceived stress score; BMI: Body mass index; OR: Odds ratio.

women having risk of developing $\mathrm{PIH}$ at $36^{\text {th }}$ week of gestation. As such PSS was significantly high and QOL was significantly low in the study group, indicating that the high-risk pregnant women had higher degrees of depression compared to the normal pregnant women. There are reports of association between depression and the higher risk of gestational hypertension. In general, women with depressive symptoms were more likely to develop hypertensive disorders of pregnancy. Reports have revealed the association between depressions with a moderately increased risk of preeclampsia. ${ }^{[25]}$

The BHR was significantly high in study group compared to control group (Table 1). Heart rate at rest is the function of vagal tone and increase in HR (resting tachycardia) represents decreased vagal activity. ${ }^{[26]}$ Recently it has been reported that increase in resting heart rate is a cardiometabolic risk and risk factor for all-cause mortality. ${ }^{[27]}$ Thus, significantly increase in BHR in study group at $36^{\text {th }}$ week of pregnancy compared to control group indicates increased CV risks in these subjects in later part of pregnancy. The level of blood pressure is the function of vascular resistance that reflects the sympathetic tone. ${ }^{[28]}$ Thus increase in SBP and DBP in study group subjects compared to control group subjects indicates the increase sympathetic tone in pregnant women with risk factors for PIH. RPP is a measure of myocardial work load and oxygen utilization. ${ }^{[21]}$ Increased RPP, especially in individuals with high blood pressure has been reported as a potential CV risk. ${ }^{[29]}$ Thus, increased BP, resting tachycardia and increased RPP in study group subjects compared to control group subjects could predispose women with risk of PIH to CV risk in their peripartum period. RPP had independent contribution to PSS, indicating that myocardial work stress could be linked to the level of depression in these high-risk women.

LF-HF ratio is the index of SVI and increase in this ratio reflects increased sympathetic activity. ${ }^{[22]}$ LF-HF ratio was significantly high in study group in comparison to control group, which confirms the presence of sympathetic overactivity in subjects with risks for PIH. There was decrease in time domain indices (RMSSD, SDNN, NN50 and pNN50) in study group subjects indicating decreased vagal drive in in pregnant women having risk of PIH. TP in general represents the magnitude of heart rate variability and the vagal potency of cardiac drive. ${ }^{[22]}$ Decrease in HRV (decreased TP) has recently been reported to be associated with cardiac morbidity and sudden cardiac death. ${ }^{[30]}$ In the present study, TP was significantly less in study group subjects in $3^{\text {rd }}$ trimesters of pregnancy. Thus, pregnant women with risk for PIH are at greater risk of cardiac morbidities and mortalities. TP and LF-HF ratio were significantly correlated and associated with PSS. These findings indicate that SVI and decreased HRV are linked the level of depression in $\mathrm{PIH}$.

Though the exact cause of decreased SVI in study group can be ascertained from the present study, one may propose that body weight and BMI in these subjects could be the mechanism for it, as increased adiposity has been reported to increase sympathetic and decrease vagal activity. ${ }^{[31,32]}$ Another important risk factor for gestational hypertension cited in some of studies is the association not only with depression, 
but also with high BMI. Obesity and depression have been cited as the most prevalent comorbidities of gestation. ${ }^{[33]}$ However, the correlation between higher BMI associated to depression and the development of gestational hypertension has not been fully established yet. Moreover, in the present study, there was no correlation of BMI with PSS in the study group.

However, the increased sympathovagal imbalance (increased LF-HF ratio) and decreased cardiovagal modulation (decreased TP) at $3^{\text {rd }}$ trimester in study group could be due to insulin resistance, atherogenic lipid profile, retrograde inflammation and oxidative stress, as HOMAIR, AI, hsCRP, IL-6, TNF- $\alpha$ and MDA were significantly high in study group subjects compared to control subjects (Table 2). Further, these parameters except hsCRP were significantly correlated with PSS (Table 3). However, only IL-6 and TNF- $\alpha$ had independent contribution to PSS (Table 4). Thus, it appears that inflammation is a major contributor to depression in PIH. As such, inflammation has been reported to be involved in the pathophysiology of depression. ${ }^{[34]}$

Increased endothelin-1 and decreased NO are the markers of vascular endothelial dysfunction and vascular inflammation. ${ }^{[35]}$ In the present study, endothelin-1 was significantly increased and NO was significantly decreased in study group (Table 1), and both of them were significantly correlated with PSS (Table 3) and had independent association with PSS (Table 4). Recently, biomarkers of vascular inflammation have been implicated in the causation of depression. ${ }^{[36]}$ Recently we have also reported the role of decreased NO in the development of CV risks in gestational hypertension. ${ }^{[37]}$ Further, decreased brain NO synthase expression has been reported in depression. ${ }^{[38]}$ Therefore, decreased NO production might possibly be among the mechanisms of depression in $\mathrm{PIH}$. Thus, from findings of the present study it appears that depression is the major cause of SVI and decreased cardiovagal modulation in PIH and retrograde inflammation and vascular endothelial dysfunction could be the potential mechanisms of depression-mediated SVI in PIH.

\section{CONCLUSION}

Findings of the present study indicate that there is considerable sympathovagal imbalance and increased cardiometabolic risks in PIH. It is likely that the depression is the major cause of SVI and decreased cardiovagal modulation in $\mathrm{PIH}$, and retrograde inflammation and vascular endothelial dysfunction could be the potential mechanisms of depression mediated SVI in PIH.

\section{ACKNOWLEDGEMENTS}

This publication is part of the intramural project of JIPMER, Puducherry granted to the first author as the principal investigator.

\section{CONFLICT OF INTEREST}

The authors declare that there is no conflict of interest.

\section{ABBREVIATIONS}

PIH: Pregnancy-induced Hypertension; SVI: Sympathovagal Imbalance; HRV: Heart Rate Variability; CMR: Cardiometabolic Risks; PSS: Perceived Stress Scale; QoL: Quality of Life; BRS: Baroreflex Sensitivity; TC: Total Cholesterol; TG: Triglyceride; LDL: Low-density Lipoprotein; VLDL: Very Low-density Lipoprotein; MDA: Malondialdehyde; AI: Atherogenic Index; hsCRP: High-Sensitive C-Reactive Protein; TNF- $\alpha$ : Tumour Necrosis Factor a, IL-6: Interleukin-6; RPP: Rate-pressure product; TP: Total Power; LFnu: Normalized Low Frequency Power; HFnu: Normalized High Frequency Power; RMSSD: The Square Root of the Mean of the Sum of the Squares of the Differences Between Adjacent NN Intervals; SDNN: Standard Deviation of Normal to Normal Interval;
NN50: The Number of Interval Differences of Successive NN Intervals Greater than 50; pNN50: The Proportion Derived by Dividing NN50 by the Total Number of NN Intervals.

\section{REFERENCES}

1. Moya J, Phillips L, Sanford J, Wooton M, Gregg A, Schuda L. A review of physiological and behavioral changes during pregnancy and lactation: potential exposure factors and data gaps. J Expo Sci Environ Epidemiol. 2014;24(5):449-58. doi: 10.1038/jes.2013.92, PMID 24424408

2. American Psychiatric Association. Diagnostic and statistical manual of mental.

3. George C, Lalitha ARN, Antony A, Kumar AV, Jacob KS. Antenatal depression in coastal South India: prevalence and risk factors in the community. Int J Soc Psychiatry. 2016;62(2):141-7. doi: 10.1177/0020764015607919, PMID 26443716.

4. Rahman A, Fisher J, Bower P, Luchters S, Tran T, Yasamy MT, Saxena S, Waheed $\mathrm{W}$. Interventions for common perinatal mental disorders in women in low- and middle-income countries: a systematic review and meta-analysis. Bull World Health Organ. 2013;91(8):593-601I. doi: 10.2471/BLT.12.109819, PMID 23940407.

5. Stein A, Pearson RM, Goodman SH, Rapa E, Rahman A, McCallum M, Howard LM, Pariante CM. Effects of perinatal mental disorders on the fetus and child. Lancet. 2014;384(9956):1800-19. doi: 10.1016/S0140-6736(14)61277-0, PMID 25455250.

6. Cohen S, Kamarck T, Mermelstein R. A global measure of perceived stress. J Health Soc Behav. 1983;24(4):385-96. doi: 10.2307/2136404, PMID 6668417.

7. Shah Z, Pal P, Pal GK, Papa D, Bharadwaj B. Assessment of the association of heart rate variability and baroreflex sensitivity with depressive symptoms and stress experienced by women in pregnancy. J Affect Disord. 2020;277:503-9. doi: 10.1016/j.jad.2020.08.039, PMID 32882507.

8. Katon WJ, Russo JE, Melville JL, Katon JG, Gavin AR. Depression in pregnancy is associated with preexisting but not pregnancy-induced hypertension. Gen Hosp Psychiatry. 2012;34(1):9-16. doi: 10.1016/j.genhosppsych.2011.09.018, PMID 22055108.

9. Raina J, El-Messidi A, Badeghiesh A, Tulandi T, Nguyen TV, Suarthana E. Pregnancy hypertension and its association with maternal anxiety and mood disorders: A population-based study of 9 million pregnancies. J Affect Disord. 2021;281:533-8. doi: 10.1016/j.jad.2020.10.058, PMID 33388464.

10. Davey DA, MacGillivray I. The classification and definition of the hypertensive disorders of pregnancy. Am J Obstet Gynecol. 1988;158(4):892-8. doi: 10.1016/0002-9378(88)90090-7, PMID 3364501.

11. Lo JO, Mission JF, Caughey AB. Hypertensive disease of pregnancy and maternal mortality. Curr Opin Obstet Gynecol. 2013;25(2):124-32. doi: 10.1097/ GCO.0b013e32835e0ef5, PMID 23403779.

12. World Health Organization. Maternal mental health. WHO Library Cataloguing in Publi-cation Data. Geneva: World Health Organization; 2016.

13. Thombre MK, Talge NM, Holzman C. Association between pre-pregnancy depression/anxiety symptoms and hypertensive disorders of pregnancy. J Womens Health (Larchmt). 2015;24(3):228-36. doi: 10.1089/jwh.2014.4902, PMID 25588112.

14. Qiu C, Sanchez SE, Lam N, Garcia P, Williams MA. Associations of depression and depressive symptoms with preeclampsia: results from a Peruvian casecontrol study. BMC Womens Health. 2007:7:15. doi: 10.1186/1472-6874-7-15. PMID 17900360.

15. Pal GK, Shyma P, Habeebullah S, Shyjus P, Pal P. Spectral analysis of heart rate variability for early prediction of pregnancy-induced hypertension. Clin Exp Hypertens. 2009;31(4):330-41. doi: 10.1080/10641960802621333, PMID 19811361

16. Pal GK, Shyma P, Habeebullah S, Pal P, Nanda N, Shyjus P. Vagal withdrawal and sympathetic overactivity contribute to the genesis of early-onset pregnancy-induced hypertension. Int J Hypertens. 2011:2011:361417. doi: 10.4061/2011/361417. PMID 21629868.

17. Pal P, Pal G, Sridhar M, Subha M, Syed H, Adithan C. Association of sympathovagal imbalance with arterial stiffness indices in women with risk factors for pregnancy-induced hypertension in first and third trimesters of gestation. Int J Clin Exp Physiol. 2014;1(2):113-9. doi: 10.4103/2348-8093.137404.

18. Subha M, Pal P, Pal GK, Habeebullah S, Adithan C, Sridhar MG. Decreased baroreflex sensitivity is linked to sympathovagal imbalance, low-grade inflammation, and oxidative stress in pregnancy-induced hypertension. Clin Exp Hypertens. 2016;38(8):666-72. doi: 10.1080/10641963.2016.1200596, PMID 27935325

19. Koschke M, Boettger MK, Schulz S, Berger S, Terhaar J, Voss A, Yeragani VK, Bär KJ. Autonomy of autonomic dysfunction in major depression. Psychosom Med. 2009;71(8):852-60. doi: 10.1097/PSY.0b013e3181b8bb7a, PMID 19779146.

20. Rifat Jahan CR, Begum S, Ferdousi S, Uddin MM. Autonomic dysfunction in major depressive disorder. Bangladesh Soc Physiol. 2014;9(1):37-41.

21. Pal GK, Adithan C, Indumathy J, Suchitra B. Myocardial works stress is linked to sympathovagal imbalance in prehypertensives. Int J Clin Exp Physiol. 2015;2(2):134-6. doi: 10.4103/2348-8093.161549

22. Heart rate variability: standards of measurement, physiological interpretation and clinical use. Task Force of the European Society of Cardiology and the North 
American Society of Pacing and Electrophysiology. Circulation. 1996;93(5):104365. doi: 10.1161/01.CIR.93.5.1043, PMID 8598068.

23. Liu C, Wang Z, Chen J, et al. Psychometric properties of the Chinese version of the perceived stress Scale in policewomen. PLOS ONE;20111(6):12-8.

24. Burckhardt CS, Anderson KL, Archenholtz B, Hägg O. The Flanagan Quality Of Life Scale: evidence of construct validity. Health Qual Life Outcomes. 2003;1:59. doi: 10.1186/1477-7525-1-59, PMID 14613563.

25. Hu R, Li Y, Zhang Z, Yan W. Antenatal depressive symptoms and the risk of preeclampsia or operative deliveries: a meta-analysis. PLOS ONE. 2015;10(3):e0119018. doi: 10.1371/journal.pone.0119018, PMID 25789626.

26. Palatini P. Heart rate and the cardiometabolic risk. Curr Hypertens Rep. 2013;15(3):253-9. doi: 10.1007/s11906-013-0342-7, PMID 23645136.

27. Jensen MT, Suadicani P, Hein HO, Gyntelberg F. Elevated resting heart rate, physical fitness and all-cause mortality: a 16-year follow-up in the Copenhagen Male Study. Heart. 2013;99(12):882-7. doi: 10.1136/heartjnl-2012-303375, PMID 23595657.

28. Pal GK, Pal P, Nivedita N. Regulation of blood pressure. In: Comprehensive textbook of medical physiology. 2nd ed. New Delhi, India: Jaypee Publications; 2019. p. 445-63.

29. White WB. Heart rate and the rate-pressure product as determinants of cardiovascular risk in patients with hypertension. Am J Hypertens. 1999;12(2 Pt 2):50S-5S. doi: 10.1016/s0895-7061(98)00280-5, PMID 10090295.

30. Kiviniemi AM, Tulppo MP, Wichterle D, Hautala AJ, Tiinanen S, Seppänen T, Mäkikallio TH, Huikuri HV. Novel spectral indexes of heart rate variability as predictors of sudden and non-sudden cardiac death after an acute myocardial infarction. Ann Med. 2007;39(1):54-62. doi: 10.1080/07853890600990375, PMID 17364451.
31. Lambert E, Sari Cl, Dawood T, Nguyen J, McGrane M, Eikelis N, Chopra R, Wong C, Chatzivlastou K, Head G, Straznicky N, Esler M, Schlaich M, Lambert G. Sympathetic nervous system activity is associated with obesity-induced subclinical organ damage in young adults. Hypertension. 2010;56(3):351-8. doi: 10.1161/HYPERTENSIONAHA.110.155663, PMID 20625075.

32. Dangardt F, Volkmann R, Chen Y, Osika W, Mårild S, Friberg P. Reduced cardiac vagal activity in obese children and adolescents. Clin Physiol Funct Imaging 2011;31(2):108-13. doi: 10.1111/j.1475-097X.2010.00985.x, PMID 21087396.

33. Franco RC, Ferreira CR, Vieira CR, Silva RR. Ethnicity, Obesity and Emotional Factors Associated With Gestational Hypertension. J Commun Health 2015;40(5):899-904. doi: 10.1007/s10900-015-0010-8, PMID 25761986

34. Lee CH, Giuliani F. The role of inflammation in depression and fatigue. Front Immunol. 2019;10:1696. doi: 10.3389/fimmu.2019.01696, PMID 31379879.

35. Donato AJ, Gano LB, Eskurza I, Silver AE, Gates PE, Jablonski K, Seals DR. Vascular endothelial dysfunction with aging: endothelin-1 and endothelial nitric oxide synthase. Am J Physiol Heart Circ Physiol. 2009;297(1):H425-32. doi: 10.1152/ajpheart.00689.2008, PMID 19465546.

36. Kalkman HO. The association between vascular inflammation and depressive disorder. Causality, Biomarkers and Targeted Treatment. Pharmaceuticals (Basel). 2020;13(5):92. doi: 10.3390/ph13050092, PMID 32408603.

37. Karthiga K, Pal GK, Dasari P, Nanda N, Velkumary S, Chinnakali P. Attenuation of baroreflex sensitivity and heart rate variability is linked to reduced levels of nitric oxide in pregnant women having risks of developing gestational hypertension. Clin Exp Hypertens. 2021;43(4):356-62. doi: 10.1080/10641963.2021.1883053, PMID 33567918.

38. Zhou QG, Zhu XH, Nemes AD, Zhu DY. Neuronal nitric oxide synthase and affective disorders. IBRO Rep. 2018;5:116-32. doi: 10.1016/j.ibror.2018.11.004, PMID 30591953.

Cite this article: Pal GK, Habeebullah S, Subha M, Pal P. Sympathovagal Imbalance, Cardiometabolic Risks and Hypertension Status are Linked to Depression in Women Having Risk Factors for Pregnancy-induced Hypertension. Int J Clin Exp Physiol. 2021;8(2):59-64. 